\title{
Spatio-temporal analysis of Pertussis using geographic information system among Iranian population during 2012-2018
}

\author{
Yousef Alimohamadi ${ }^{1}$, Seyed Mohsen Zahraei ${ }^{2}$, Manoochehr Karami $^{3}$, Mehdi Yaseri ${ }^{1}$, Mojtaba Lotfizad ${ }^{4}$, \\ Kourosh Holakouie-Naieni*1(D)
}

Received: 31 Jul 2019

Published: 18 Mar 2020

\section{Abstract}

Background: In spite of existing vaccination programs in many countries, outbreaks of pertussis are still reported. In Iran, the suspected and confirmed cases of pertussis are reported annually. Due to the lack of similar studies, the purpose of the current study was to determine the Spatio-temporal distribution of Pertussis using Geographic Information System (GIS) to identify high-risk areas in Iran during 2012-2018.

Methods: In the current cross-sectional study, registered data in the department of vaccine-preventable diseases in the Iranian ministry of health were used. To assess the temporal trend, the Cochran-Armitage test was used. To show the spatial distribution and to identify hotspot areas, Choropleth map and Getis-Ord Gi statistics were used. All analyses performed by Arc.map10.5, Stata 15 and Excel 2010.

Results: The incidence of suspect pertussis cases had an increasing trend but did not have a linear trend $(\mathrm{p}=0.06)$. Most of the cases happened in under 1 year infants (62.66\%). The incidence of reported cases in northern areas was higher than in the Southern areas. The Zanjan had the most reported cases during the understudied period with a median of 7.63 reported cases per 100,000 . The clustering of infection and hotspots were identified in northern areas of Iran including Qazvin, Qom, Markazi, and Hamadan.

Conclusion: Our results showed that the cumulative incidence of reported cases is increasing. The northern provinces had the highest incidence of Pertussis. Therefore, the causes of this spatio-temporal pattern of pertussis should be determined. Also, supervision on vaccination programs in high-risk areas is recommended.

Keywords: Spatio-temporal, Bordetella pertussis, Iran

Conflicts of Interest: None declared

Funding: Tehran University of Medical Sciences

\section{*This work has been published under CC BY-NC-SA 1.0 license. Copyright $\odot$ Iran University of Medical Sciences}

Cite this article as: Alimohamadi Y, Zahraei SM, Karami M, Yaseri M, Lotfizad M, Holakouie-Naieni K. Spatio-temporal analysis of Pertussis using geographic information system among Iranian population during 2012-2018. Med J Islam Repub Iran. 2020 (18 Mar);34:22. https://doi.org/10.47176/mjiri.34.22

\section{Introduction}

Pertussis or whooping cough is a vaccine-preventable respiratory disease that is mainly caused by Bordetella pertussis $(1,2)$. This infection may present with mild symptoms to fatal complication especially in under 3-

Corresponding author: Dr Kourosh Holakouie-Naieni, holakoik@hotmail.com

1. Department of Epidemiology and Biostatistics, School of Public Health, Tehran University of Medical Sciences, Tehran, Iran

2. Center for Communicable Diseases Control, Ministry of Health and Medical Education, Tehran, Iran

3. Research Center for Health Sciences, Hamadan University of Medical Sciences, Hamadan, Iran

4. School of Electrical \& Computer Engineering, Tarbiat Modares University, Tehran, Iran month infants (3) and it is one of the main causes of morbidity and mortality among neonates and infants (4). Before the introduction of vaccines, the epidemics of pertussis were reported each 2 to 5 years in the susceptible

$\uparrow$ What is "already known" in this topic:

The use of spatio-temporal analysis with geographic information system (GIS) is a beneficial epidemiologic method to identify high-risk areas about different diseases. In Iran, there is no similar study about the spatial distribution of Pertussis.

\section{$\rightarrow$ What this article adds:}

This study performed to determine the spatio-temporal distribution of suspect cases of pertussis in Iran. The incidence of suspect pertussis cases had a non-linear increasing trend. The incidence of reported cases in Northern areas was higher than the Southern areas. 
population. Although the presentation of the vaccine has reduced the incidence of the disease, it does not have any effect on reducing epidemic intervals (5). In spite of developing immunization programs in many countries, pertussis remains the important cause of mortality in children leading to about 200,000 annual deaths in under 5 children (6). About 10 million cases of pertussis occur annually in the world, which most of them(about 90 to 95\%) occurred in developing countries $(7,8)$. This reported number had an increasing trend in many countries with high coverage of immunization, and the incidence has shifted the adults $(9,10)$. This indicates challenges in controlling this infection (11). In Iran such as other developing countries, before conducting the vaccination program, pertussis was the most common public health problem during the past decades. According to World Health Organization (WHO) recommendations, the Iranian Advisory Committee for Immunization Practices (I-ACIP) has initiated EPI (the WHO's Expanded Program on Immunization) for the prevention of vaccine-preventable diseases such as pertussis since 1983 (12). At present, the coverage rate of many vaccines in Iran is acceptable, and the pertussis vaccine coverage in Iran for 1991,1992 and 2018 was reported approximately $87 \%, 95 \%$ and $99 \%$, respectively $(13,14)$. However, the immunization against pertussis cannot produce long immunity (15); hence an increasing trend of new cases of pertussis is possible (16). In Iran, the reported cases of pertussis had an increasing trend in recent years (17). Also, it seems the distribution of pertussis has a spatial pattern. The geographic information system (GIS) is a beneficial epidemiologic method to identify high-risk areas about different diseases (18). This method was used to identify high-risk areas in many infectious diseases $(19,20)$. Identification of areas with high incidence and prevalence also spatial and temporal distributions of infectious diseases can play an important role in designing prevention programs, as well as for health policymakers. Due to the lack of similar research on Pertussis, the purpose of the current study was to determine the spatio-temporal distribution of pertussis from 2012 to 2018 in Iran and identification of hotspot provinces for the Iranian health policymakers to better plan for preventing and controlling the disease in high-risk provinces of Iran.

\section{Methods}

\section{Study area}

Iran is a country located in the Middle East and West Asia. The total area of Iran is about $1,648,195 \mathrm{~km} 2$, and according to the results of the last census in 2016, the total population is about 80 million. Iran has common borders with different countries. In the northwest area it has common borders by Armenia and the Republic of Azerbaijan; in the northern areas by the Caspian Sea, in the northeast by Turkmenistan, in the east by Afghanistan and Pakistan, in the south by the Persian Gulf and the Gulf of Oman and in the west by Turkey and Iraq. According to the latest country divisions, Iran is divided into 31 provinces (21).

\section{Pertussis data}

In Iran, the surveillance system for pertussis is accord- ing to suspect cases of pertussis. The suspect case of pertussis defined as a person who had a cough lasting $\geq 2$ weeks with at least one of the following symptoms, paroxysms (fits) of coughing, inspiratory whooping, posttussive vomiting, or vomiting without other apparent cause and apnea (only in $<1$ year of age) (13). All suspect cases of pertussis from different health centers reported to the Iranian Centers for Disease Control and Prevention in the ministry of health. In this study, all the suspected cases of pertussis that were registered in the department of vaccine-preventable diseases in the Iranian Centers for Disease Control and Prevention from March 2012 to March 2018 were used.

\section{Population data}

In the current study, the total Iranian population according to different provinces from 2012 to 2018 was used. The population size in each year was estimated according to the population Growth formula as follow:

$\mathrm{P}_{\mathrm{t}}: \mathrm{P}_{0}(1+\mathrm{r})^{\mathrm{t}}$

Were $P_{t}$ is the population size at time $t$ (in the current study was 2016), $\mathrm{P}_{0}$ (in the current study was 2011) is the population size at time zero and $\mathrm{r}$ is average annual population growth. The needed data extracted from statistic center of Iran (22).

\section{Cumulative Incidence calculation}

The annual Cumulative Incidence of pertussis per 100,000 populations calculated as follow:

Annual Cumulative Incidence:

$\frac{\text { number of new cases in year of } \mathrm{X}}{\text { total at risk person in year of } x} * 100,000$ (23)

\section{Temporal analysis}

To assess the trend of cumulative incidence, the Cochran-Armitage test for linear trend was used. The test evaluates the increasing or decreasing trend of incidence of the cases over time as well as its statistical significance (20).

\section{Choropleth map}

A Choropleth map is a beneficial schematic tool that uses to show the distribution of events or diseases. This map comprises a range of colors to show events changes in the layers of polygons produced at the provincial level. To show spatial changes of events over time, this map can use time frames as years or more than one year of events (for example, two, three, etc.). The determination of the time frame is dependent on the nature of the understudy event and years. If the epidemiological changes of understudy events occurred in a short time or the number of understudied years was few it is better the shorter time interval considered and vice versa. Considering these points in the current study, a series of Choropleth maps for the incidence proportion of pertussis in the time frame of one year were created (23).

\section{Hotspot Identification}

Hotspots are locations that clustering of diseases or events is significantly different from other areas. Hotspot 
analysis was used to identify the spatial clusters of diseases. Getis-Ord $G_{i}$ statistics were used to identify hotspots. A high score of this index with a lower p-value indicates the clustering of pertussis. The formula of the $G_{i}$ statistics is as follows:

$$
G_{i}^{*}=\frac{\sum_{j=1}^{n} w_{i, j} x_{j}-\bar{X} \sum_{j=1}^{n} w_{i, j}}{S \sqrt{\frac{n \sum_{j=1}^{n} w_{i, j}^{2}-\left(\sum_{j=1}^{n} w_{i, j}\right)^{2}}{n-1}}}
$$

Where $x_{j}$ is the incidence of pertussis for province $\mathrm{j}$, $w_{i, j}$ is the spatial weight between province $\mathrm{i}$ and $\mathrm{j}, \mathrm{n}$ is the total number of provinces. The $\bar{X}$ and S, are calculated as follows(23):

$$
\begin{aligned}
& \bar{X}=\frac{\sum_{j=1}^{n} x_{j}}{n} \\
& S=\sqrt{\frac{\sum_{j=1}^{n} x_{j}^{2}}{n}-(\bar{X})^{2}}
\end{aligned}
$$

All analyses were performed using Arc.map10.5, Stata
15 end Excel 2010, considering $\alpha$ : 0.05 as a Statistical significant level.

\section{Results}

\section{Descriptive statistics}

The total number of registered pertussis suspected cases from 20 March 2012 to 19 March 2018 among the Iranian population was about 7775 cases. The mean age of the registered cases was $6.25 \pm 19.03$ years. $4872(62.66 \%)$ of cases occurred in under 1-year infants. 3,714 (47.87\%) of total cases were females and 4,045 $(52.13 \%)$ of cases were males.

\section{Temporal Distribution}

In terms of the trend analysis over time, the incidence of reported cases in different years had an increasing trend. This was not a linear trend $(p=0.06)$. The most reported cases were seen from 20 March 2013 to 19 March 2014 (1.87 per 100,000) and 20 March 2017 to 19 March 2018 (1.81 per 100,000). The lowest reported cases were seen from 20 March 2014 to 19 March 2015 (1.28 per 100,000) (Fig. 1).

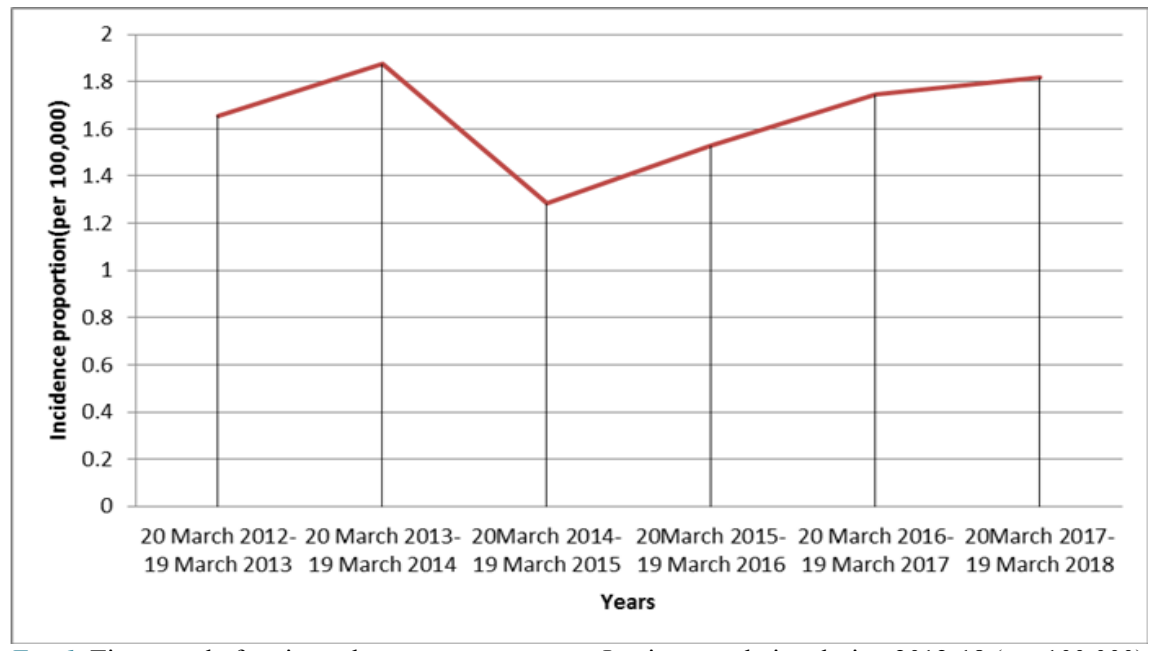

Fig. 1. Time trend of registered suspect cases among Iranian population during 2012-18 (per 100,000)

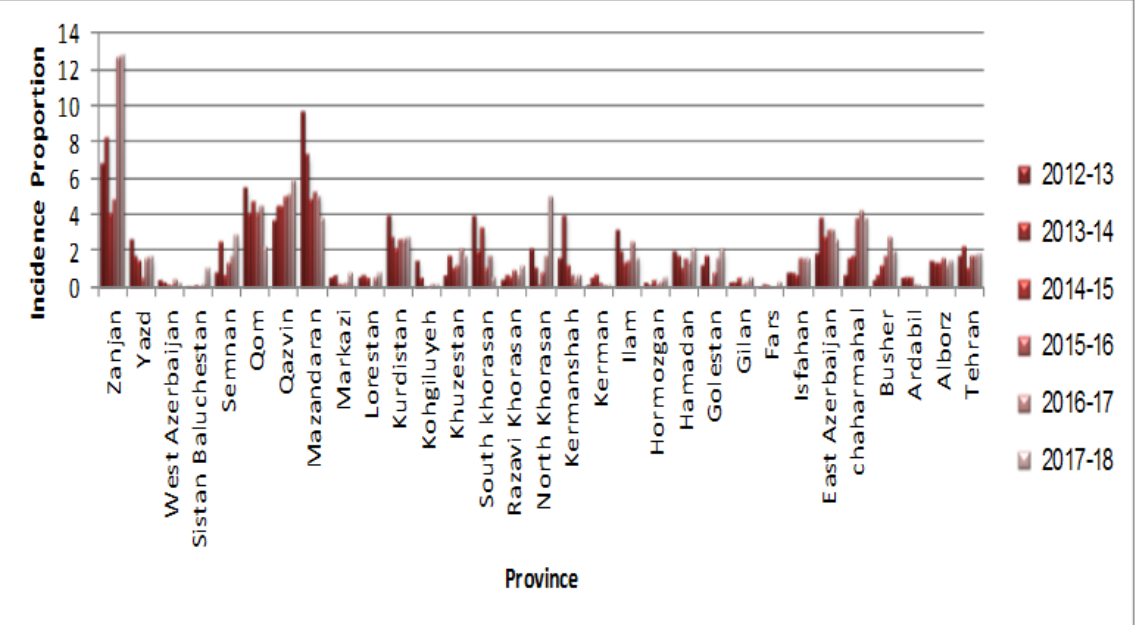

Fig. 2. The cumulative incidence of suspect pertussis cases (per 100,000) in a different province of Iran during $2012-18$ 


\section{Spatial distribution}

Overall, the most cumulative incidence of suspect pertussis cases (per 100,000 population) during the study period (March 2012 to March 2018) was seen in provinces of Zanjan, Mazandaran, Qazvin, and Qom with the median of reported cases $7.6,5.1,4.81$, and 4.38 , respectively. The lowest cumulative incidence of cases was reported from provinces of Fars, Sistan \& Baluchestan, West Azer- baijan and Hormozgan, respectively (Figs. 2 and 3). The most of incidence cases in 20 March 2012 to 19 March 2013, 20 March 2013 to 19 March 2014, 20 March 2014 to 19 March 2015, 20 March 2015 to 19 March 2016, 20 March 2016 to 19 March 2017 and 20 March 2017 to 19 March 2018 were reported from Mazandaran(9.79 per 100,000), Zanjan (8.33 per 100,000), Mazandaran (4.87 per 100,000), Mazandaran (5.30 per 100,000) Zanjan

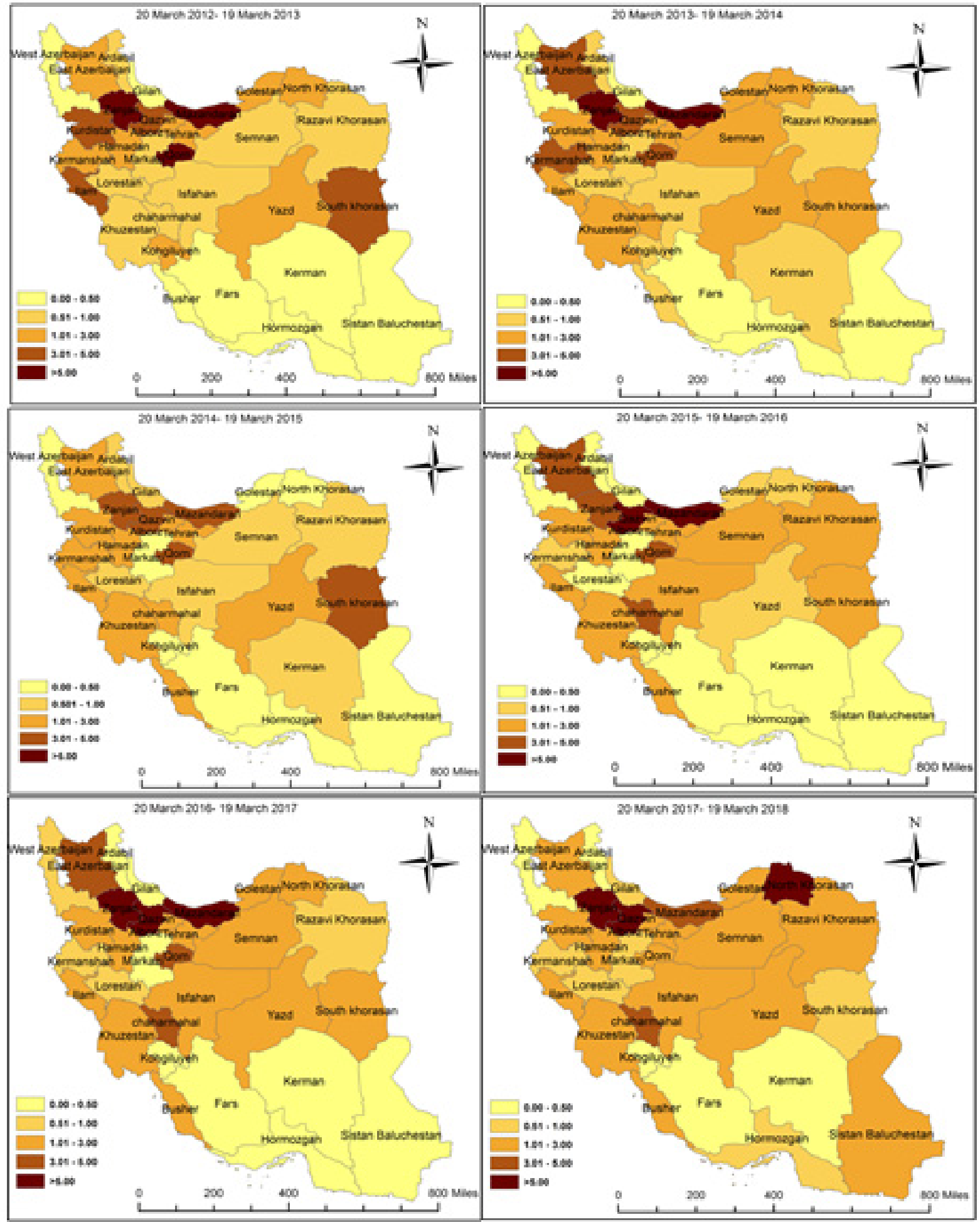

Fig. 3. Choropleth map of cumulative incidence of suspect cases of pertussis (per100, 000) in Iran during 2012-18 
(12.76 per 100,000$)$ and Zanjan (12.85 per 100,000) respectively (Fig. 3).

\section{Hotspots}

From 20 March 2012 to 19 March 2013, Gilan, Qazvin, Alborz, Hamadan, and Markazi had the highest incidence of suspected pertussis cases (per 100,000) compared to the overall average and considered as hotspots $(\mathrm{p}<0.05)$. From 20 March 2013 to 19 March 2014, Qazvin had the most incidence rate of pertussis cases and identified as a hot spot $(\mathrm{p}<0.01)$. On 20 March 2014 to 19 March 2015, Gilan, Zanjan, Qazvin, Alborz, Hamadan, Qom, and Markazi identified as hotspot areas because of the cumulative incidence of pertussis cases in these areas was higher than the overall average of the country $(\mathrm{p}<0.05)$. From 20 March 2015 to 19 March 2016, Hamadan, Markazi, and Qom provinces were hotspots $(\mathrm{p}<0.01)$. In this period, Kerman province had lower incidence cases of pertussis than the overall average of the country, so-identified as a coldspots $(\mathrm{p}<0.05)$. From 20 March 2016 to 19 March 2017, Hamadan, Markazi and Qom provinces considered as hotspots $(\mathrm{p}<0.05)$. Qazvin identified as a hotspot from 20 March 2017 to 19 March 2018 with the highest incidence cases of suspect pertussis cases $(\mathrm{p}<0.05)$ (Fig. 4).

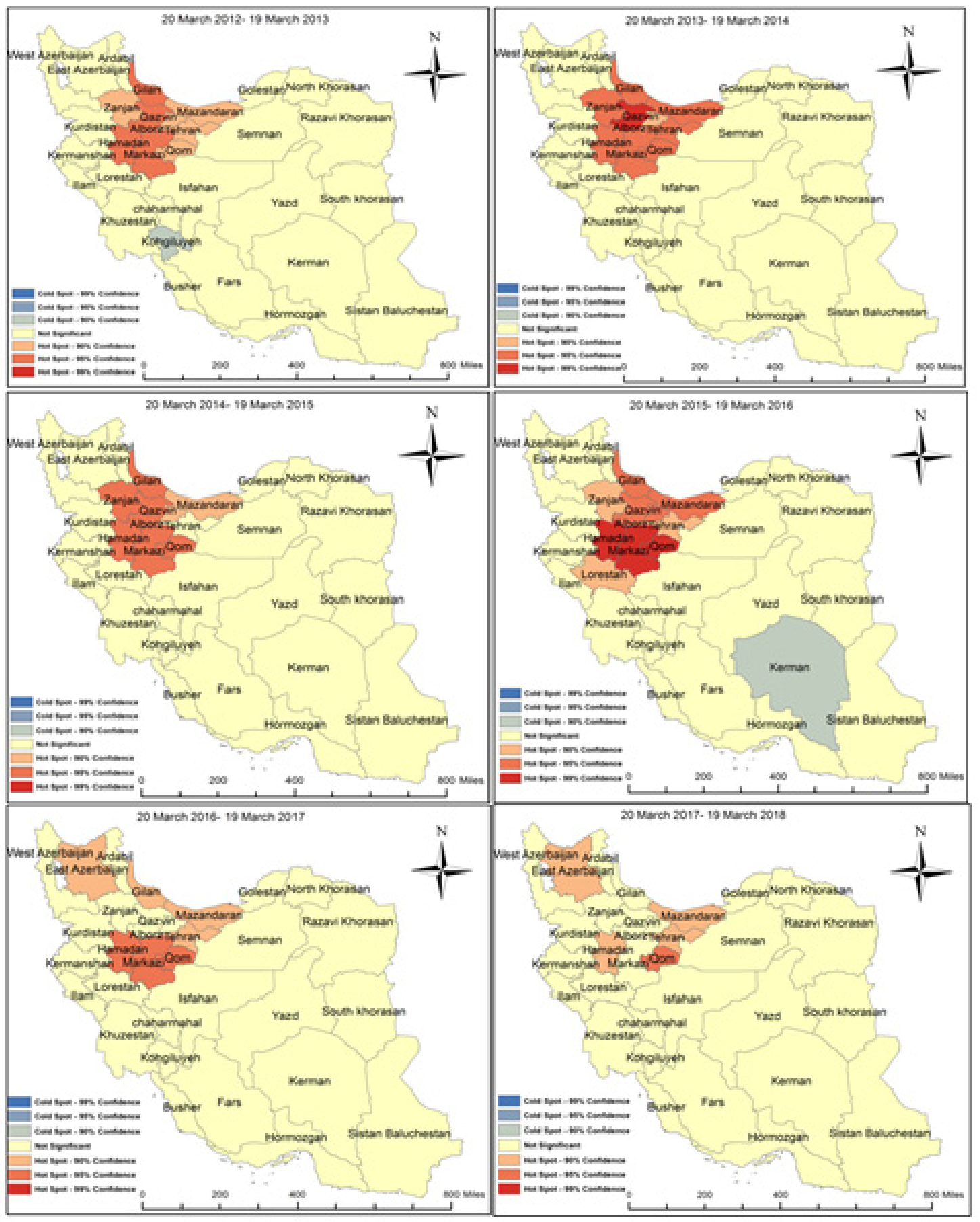

Fig. 4. The identified hotspots of pertussis cases in Iran during 2012-18 


\section{Discussion}

According to the results of the current study, the mean age of the suspect cases of pertussis was about 6.25 years, with a standard deviation of 19.03 years. It means unlike the traditional opinion, pertussis is not a neonatal and infant's specific infection and it can affect all age groups $(24,25)$. According to the results of a systematic review and meta-analysis, immunity level decreases every year after injecting the last dose of DTaP vaccine, and 8.5 years after the last vaccination, only 10 percent would be immune against pertussis (26). So a decrease in the immunity level can lead to an increased incidence of pertussis at older ages (27). This finding confirmed by other studies $(28,29)$.

According to another study, the trend of pertussis incidence in Iran was increasing from 2006 to 2011 (30). This finding is confirmed by the results of the current study. According to our results, the trend of suspect pertussis cases from 2012 to 2018 had a non-linear increasing trend. There were many assumptions for the increasing trend and re-emerging of this bacterial infection in different countries, including improving the sensitivity of surveillance system, improving diagnostic methods, raising awareness about the disease, as well as performing incomplete vaccinations, immunosuppression due to the vaccine or natural infection and bacterial compatibility with immunity that is applied by vaccines (31). Also, the role of the opponent's groups of vaccination should be regarded (32, 33). This group can have an effective role in this reemerging. Because due to low coverage of vaccination programs in the population, the number of susceptible cases will be increased and due to this, re-emerging and occurrence of outbreaks of vaccine-preventable diseases will be possible. Also, the immigration of susceptible populations from endemic countries should be considered. The increased immigration of the suspect population to other regions can have an important role in increasing the number of reported cases with an increase in the number of susceptible populations.

Different studies showed the spatial patterns of many infectious diseases such as influenza, dengue hemorrhagic fever, measles, West Nile virus, and Ebola (34-36). Several factors can have a strong effect on the spatial distribution of diseases, among which two important ones are human and ecological-related factors. Human factors include the level of herd immunity, population size and socioeconomic status, and accessibility to public health services in different areas. As an example, the lack of herd immunity in a province can lead to outbreaks and a high incidence of many infectious diseases. Ecological factors that can have a role in the spatial distribution of diseases include climate factors like temperature, rainfall, arid condition, dry farm, and sparse forest regions (37-39). According to our results, the incidence of suspect pertussis cases have spatial pattern and cumulative incidence of this infection in the North of Iran like Mazandaran, Gilan, Zanjan and North Khorasan was more than the Southern areas. Moreover, the spatial clusters of suspect cases were observed in Qazvin, Hamadan, and Qom and Markazi provinces. It means that the incidence of reported cases of pertussis in these provinces and their neighbors was higher than the average of the country and they are high-risk areas for pertussis. The presence of variation in the incidence of pertussis cases among different regions may be due to different factors such as low level of immunity system against the disease and the presence of susceptible individuals, and different weather conditions. Besides, to mention effective factors on the spatial distribution of diseases, the sensitivity of the surveillance system in different provinces should be considered. The higher sensitivity of surveillance systems can lead to higher diagnosis and reporting of cases and vice versa. So the higher incidence of reported cases in some provinces such as Mazandaran and Zanjan may be due to the higher sensitivity of the surveillance system in mentioned provinces. Therefore, for the decreasing effect of the sensitivity of the surveillance system on the heterogeneity of spatial distribution, this parameter should be assessed and adjusted in different provinces. There was some limitation in the current study. Firstly, this study was conducted according to the registered cases by the surveillance system, so the validity of results depends on the quality and validity of the registered data. Secondly, reported cases in different provinces could affect by the sensitivity of the surveillance system in each province so it can lead to the observation of differences in the spatial distribution of the disease.

\section{Conclusion}

The trend of reported pertussis cases among the Iranian population was increasing; also, the distribution of this infection had a spatial pattern, and the incidence of it among different areas was not uniform. The northern areas of Iran have more incidence proportion; also, clustering of suspect cases of pertussis was observed in these areas. The mentioned high-risk areas should be considered to develop more supervision on prevention programs such as vaccination.

\section{Acknowledgements}

The authors would like to express their appreciation for the Iranian Ministry of Health and Center for Communicable Diseases Control for their constant support and collaboration. This article was extracted from the Ph.D. thesis by Yousef Alimohamadi and financially supported by Tehran University of Medical Sciences. Also, this study approved by the ethical committee of Tehran University of Medical Sciences with ID: IR.TUMS.SPH.REC. 1397.276.

\section{Conflict of Interests}

The authors declare that they have no competing interests.

\section{References}

1. Choisy M, Rohani P. Changing spatial epidemiology of pertussis in continental USA. Proc Biol Sci. 2012;279(1747):4574-81.

2. Medu O, Anderson M, Enns A, Wright J, Dunlop T, Kapaj S, et al. Predictors of pertussis outbreak in urban and rural municipalities of Saskatchewan, Canada. Can J Public Health. 2018;109(3):362-368.

3. Donegan K, King B, Bryan P. Safety of pertussis vaccination in pregnant women in UK: observational study. BMJ. 2014;349:g4219. 
4. Moore A, Ashdown HF, Shinkins B, Roberts NW, Grant CC, Lasserson DS, et al. Clinical characteristics of pertussis-associated cough in adults and children: a diagnostic systematic review and meta-analysis. Chest. 2017;152(2):353-67.

5. Crespo I, Soldevila N, Muñoz P, Godoy P, Carmona G, Domínguez A. Geographical differences in whooping cough in Catalonia, Spain, from 1990 to 2010. BMC Public Health. 2014;14(1):268.

6. Atkins KE, Fitzpatrick MC, Galvani AP, Townsend JP. Costeffectiveness of pertussis vaccination during pregnancy in the United States. Am J Epidemiol. 2016;183(12):1159-70.

7. Bart MJ, Harris SR, Advani A, Arakawa Y, Bottero D, Bouchez V, et al. Global population structure and evolution of Bordetella pertussis and their relationship with vaccination. MBio. 2014;5(2):e01074-14.

8. Almaw L, Bizuneh H. Pertussis outbreak investigation in Janamora district, Amhara Regional State, Ethiopia: a case-control study. Pan Afr Med J. 2019;1(34):65.

9. Magpantay F, Rohani P. Dynamics of pertussis transmission in the United States. Am J Epidemiol. 2015;181(12):921-31.

10. Kauhl B, Heil J, Hoebe CJ, Schweikart J, Krafft T, Dukers-Muijrers $\mathrm{NH}$. Is the current pertussis incidence only the results of testing? A spatial and space-time analysis of pertussis surveillance data using cluster detection methods and geographically weighted regression modelling. PloS One. 2017;12(3):e0172383.

11. Campbell PT, McVernon J, Geard N. Determining the best strategies for maternally targeted pertussis vaccination using an individual-based model. Am J Epidemiol. 2017;186(1):109-17.

12. Saffar MJ, Ghorbani G, Hashemi A, Rezai MS. Pertussis resurgence in a highly vaccinated population, Mazandaran, North of Iran 20082011: an epidemiological analysis. Indian J Pediatr. 2014;81(12):1332-6.

13. Ghorbani GR, Zahraei SM, Moosazadeh M, Afshari M, Doosti F. Comparing Seasonal Pattern of Laboratory Confirmed Cases of Pertussis with Clinically Suspected Cases. Osong Public Health Res Perspect. 2016;7(2):131-7.

14. WHO vaccine-preventable diseases: monitoring system. 2019 global summary [Internet]. World Health Organization. 2019

15. Cherry JD. Epidemic pertussis in 2012 - the resurgence of a vaccine-preventable disease. N Engl J Med. 2012;367(9):785-7.

16. Shahcheraghi F, Lotfi MN, Nikbin VS, Shooraj F, Azizian R, Parzadeh M, et al. The first macrolide-resistant Bordetella pertussis strains isolated from Iranian patients. Jundishapur J Microbiol. 2014; 7(6):e10880.

17. Sedighi I, Karimi A, Amanati A. Old Disease and New Challenges: Major Obstacles of Current Strategies in the Prevention of Pertussis. Iran J Pediatr. 2016;26(4).

18. Salimi M, Jesri N, Javanbakht M, Farahani LZ, Shirzadi MR, Saghafipour A. Spatio-temporal distribution analysis of zoonotic cutaneous leishmaniasis in Qom Province, Iran. J Parasit Dis. 2018;42(4):570-6.

19. Khazaei S, Karami M, Mohammadbeigi A, Ayubi E, Shojaeian M, Mansouri K, et al. Spatio-Temporal analysis of brucellosis in Hamadan Province, West of Iran: 2009-2015. Adv Hum Biol. 2018;8(3):145.

20. Pakzad R, Dabbagh-Moghaddam A, Mohebali M, Safiri S, Barati M. Spatio-temporal analysis of cutaneous leishmaniasis using geographic information system among Iranian Army Units and its comparison with the general population of Iran during 2005-2014. J Parasit Dis. 2017;41(4):1114-22.

21. Khoshdel A, Alimohammadi M, Sepandi M, Alimohamadi Y, Jalali P, Janani M. Spatio-temporal analysis of colorectal cancer using a geographic information system in the Iranian military community during the period 2007-2016. J R Army Med Corps 2019:jramc2018-001151.

22. Statistical center of Iran. 2019. Available from: https://www.amar. org.ir/english.

23. Holakouie-Naieni K, Mostafavi E, Boloorani AD, Mohebali M, Pakzad R. Spatial modeling of cutaneous leishmaniasis in Iran from 1983 to 2013. Acta Trop. 2017;166:67-73.

24. Rothstein E, Edwards K. Health burden of pertussis in adolescents and adults. Pediatr Infect Dis J. 2005;24(5):S44-S7.

25. Kuchar E, Karlikowska-Skwarnik M, Han S, Nitsch-Osuch A. Pertussis: history of the disease and current prevention failure. Pulmonary Dysfunction and Disease: Springer; 2016. p. 77-82.

26. McGirr A, Fisman DN. Duration of pertussis immunity after DTaP immunization: a meta-analysis. Pediatrics. 2015;135(2):331-43.
27. Skowronski DM, De Serres G, MacDonald D, Wu W, Shaw C, Macnabb J, et al. The changing age and seasonal profile of pertussis in Canada. Int J Infect Dis. 2002;185(10):1448-53.

28. Jõgi P, Oona M, Toompere K, Lutsar I. Estimated and reported incidence of pertussis in Estonian adults: a seroepidemiological study. Vaccine. 2015;33(38):4756-61.

29. Chlibek R, Smetana J, Sosovickova R, Fabianova K, Zavadilova J, Dite $\mathrm{P}$, et al. Seroepidemiology of whooping cough in the Czech Republic: estimates of incidence of infection in adults. Public Health. 2017; 150:77-83.

30. Khazaei S, Ayubi E, Mansori K, Khazaei S. Pertussis incidence by time, province and age group in Iran, 2006-2011. Iran J Public Health 2016;45(11):1525-7.

31. Tan T, Dalby T, Forsyth K, Halperin SA, Heininger U, Hozbor D, et al. Pertussis across the globe: recent epidemiologic trends from 2000 to 2013. Pediatr Infect Dis J. 2015;34(9):e222-e32.

32. Leask J, McIntyre P. Public opponents of vaccination: a case study. Vaccine. 2003;21(32):4700-3.

33. Blume S. Anti-vaccination movements and their interpretations. Soc Sci Med. 2006;62(3):628-42.

34. Choisy M, Rohani P. Changing spatial epidemiology of pertussis in At present continental USA. Proc Biol Sci. 2012;279(1747):4574-81.

35. Ostfeld RS, Glass GE, Keesing F. Spatial epidemiology: an emerging (or re-emerging) discipline. Trends Ecol Evol. 2005;20(6):328-36.

36. Wen TH, Lin NH, Chao DY, Hwang KP, Kan CC, Lin KCM, et al. Spatial-temporal patterns of dengue in areas at risk of dengue hemorrhagic fever in Kaohsiung, Taiwan, 2002. Int J Infect Dis. 2010;14(4):e334-e43.

37. Ghatee MA, Sharifi I, Haghdoost AA, Kanannejad Z, Taabody Z, Hatam G, et al. Spatial correlations of population and ecological factors with distribution of visceral leishmaniasis cases in southwestern Iran. J Vector Borne Dis. 2013;50(3):179.

38. Broutin H, Elguero E, Simondon F, Guégan J. Spatial dynamics of pertussis in a small region of Senegal. Proc Biol Sci. 2004;271(1553):2091-8.

39. Siegel C, Davidson A, Kafadar K, Norris JM, Todd J, Steiner J. Geographic analysis of pertussis infection in an urban area: a tool for health services planning. Am J Public Health. 1997;87(12):2022-6. 